\title{
Russian predicatives and the ontology of states
}

\author{
Anton Zimmerling \\ Institute of linguistics, Russian Academy of Science/ \\ Puskhin state Russian language Institute, Moscow, Russia \\ fagraey64@hotmail. com
}

\begin{abstract}
Basing on the frequency dictionary of Russian predicatives, I measure the volume of the lexical class of nonagreeing predicatives licensing the productive dative-predicative sentence pattern, where the predicative assigns dative case to its animate subject. The tested vocabulary includes 422 elements. Their frequency rates are derived from the main corpus of RNC using an approximation - the number of hits in the context "predicative + dative subject in $1 \mathrm{Sg}$ " in the window $\{-1 ; 1\}$. I argue that the Russian dative-predicative construction has an invariant meaning of internal state, i.e. spaciotemporal stative situation with a priority argument. However, most predicatives licensing dative-predicative structures in Russian also express external states, i.e. spaciotemporal stative situations without a priority argument, if used without overt referential dative subject. This can be proved both for words denoting physical sensations, cf. $X-y$ kholodno ' $\mathrm{X}$ is cold' vs kholodno 'It is cold' and for some words denoting affections, cf. tosklivo 'dreary', 'sad', $X$-y tosklivo ' $\mathrm{X}$ feels sad' vs zdes' tosklivo 'It's dreary here'. The shift from internal state to external state is licensed in Russian. If a lexical item has regular uses in the dative-predicative structure, it generally can express the meaning of external state outside this structure. The reverse if false: if a lexical item has regular uses as an external state, cf. vetreno 'windy', pyl'no 'dusty', it only can have infrequent side uses with a dative subject. This asymmetry is confirmed by the corpus data. I check an additional list of words with the meaning of external state, measure their frequency rate in the context "predicative + dative subject in $1 \mathrm{Sg}$ " in the window $\{-1 ; 1\}$ and compare them to standard dative predicatives.
\end{abstract}

Keywords: ontology, internal states, external states, predicatives, corpus grammar, Russian language

DOI: $10.28995 / 2075-7182-2021-20-738-748$

\section{Русские предикативы и онтология состояний}

\author{
Циммерлинг А. В. \\ Институт языкознания РАН/Государственный институт \\ русского языка имени А. С. Пушкина, Москва, Российская федерация \\ fagraey@hotmail.com
}

\begin{abstract}
Аннотация
В статье определяются предикатные значения внутреннего и внешнего состояния, строится онтология русской конструкции с предикативами дативно-предикативной структуры и проверяется гипотеза о том, что данная конструкция имеет инвариантное значение внутреннего состояния. Переход от внешних состояний к внутренним в русском языке затруднен, в то время как переход от внутренних состояний к внешним регулярен. Предикативы дативно-предикативной структуры при устранении позиции семантического субъекта могут выражать значение внешнего состояния. В этом случае предикатив может описывать внешне наблюдаемую референтную ситуацию, оцениваемую одинаково любым наблюдателем. Глагольные предложения с качественным наречием, коррелятивным предикативу ДПС, проецируют структуру события, содержащую отсылку либо к внутреннему, либо к внешнему состоянию.
\end{abstract}

Ключевые слова: онтология, внутренние состояния, внешние состояния, предикативы, корпусная грамматика, русский язык 


\section{1 Варьирование и лингвистические модели}

\section{1 Варьирование в лексике и грамматике}

Модели классической лингвистики опираются на понятие инварианта. Варьирование изучают специальные дисциплины - диалектология, которая исследует территориальное распределение единиц и конструкций в идиомах, признаваемых вариантами некоторого языка [Henry 2005], coциолингвистика и корпусная лингвистика. Варьирование в области словаря касается корреляций между корнем и значением. Варьирование в области грамматики касается ограничительных условий, регулирующих воспроизводство правильно построенных выражений. При параметризации грамматик языков мира можно с помощью одного и того же набора параметров описать как внутриязыковое, так и межъязыковое варьирование.

\section{2 Конструкции}

Описательная лингвистика называет конструкциями структурные схемы, ограничивающие отбор лексического материала ${ }^{1}$. Такое понимание совместимо с изучением внутриязыкового варьирования. Предположим, что конструкция С строится при помощи лексем из множества $\{\mathrm{a}, \mathbf{b}, \mathrm{c}, \mathbf{d}$, $\mathrm{e}, \mathrm{f}, \mathrm{g}, \mathrm{h}\}$, но в идиоме $\mathrm{L}_{1}$ используются только $\{\mathrm{a}, \mathbf{b}, \mathrm{c}, \mathbf{d}\}$, в идиоме $\mathrm{L}_{2}$ - только $\{\mathbf{b}, \mathbf{d}, \mathrm{e}, \mathrm{f}\}$, а в идиоме $\mathrm{L}_{3}$ - только $\{\mathbf{b}, \mathbf{d}, \mathrm{g}, \mathrm{h}\}$ Тогда элементы множества $\{\mathrm{b}, \mathrm{d}\}$, представленные в каждом идиоме, можно признать ядром $\mathrm{C}$, а прочие элементы - его расширением в идиомах $\mathrm{L}_{1-3}$. Гипотеза о том, что в разных идиомах реализуется одна и та же конструкция, держится на допущении о том, что у С есть инвариантное значение, которое сохраняется при лексических заменах типа $\mathrm{a}, \mathrm{c} \rightarrow \mathrm{e}, \mathrm{f}$. Кроме того, гипотеза о том, что C поддерживается в языке L лексемами из множества $\{\mathrm{a}, \mathbf{b}, \mathbf{c}, \mathbf{d}, \mathrm{e}, \mathrm{f}, \mathrm{g}, \mathrm{h}\}$, опирается на допущение о возможности вывести усредненную форму языка L на основе пересечения или объединения грамматик и словаря идиомов $\mathrm{L}_{1}, \mathrm{~L}_{2}$, L $\mathrm{L}_{3}$. Границы варьирования проверяются на основе распределения конструкций $\mathrm{C}_{1} . . \mathrm{C}_{\mathrm{n}}$ в разных идиомах $\mathrm{L}$, или в корпусе текста, где можно установить частотность элементов словаря конструкций. При комбинировании корпусных и социолингвистических методов в благоприятном случае можно установить корреляцию между частотностью элемента или комбинации элементов в корпусе и степенью их одобрения носителями языка, см. описание двойного эксперимента в [Zimmerling 2017].

Инвариантное значение конструкции, если жестких запретов на пополнение ее словаря нет, проверяется двумя способами. Одним из них является уточнение набора денотативных ситуаций, покрываемых ее употреблением, т.е. построение онтологии конструкиии. Другим способом является уточнение таксономической семантики, т.е. ниши, занимаемой данной конструкцией языка L в общей таксономии предикатных типов, приложимой к разным языкам.

\section{2 Предикативы дативно-предикативной структуры в русском языке}

\section{1 Схема и семантика}

Предикативы дативно-предикативной структуры (далее - ДПС) есть несогласуемые неглагольные слова, реализующимися в схеме дат. п. лица — связка - предикатив. Н.С.Поспелов указал три характеристики конструкции ДПС: 1) наличие у несогласуемого предикатива беспредложной валентности на одушевленный актант в дат. п. 2) связь между схемой ДПС и предикатным значением «состояния»; 3) отсутствие у предикатива ДПС канонического подлежащего в имен. п. [Pospelov 1955]. Мы принимаем анализ Поспелова и разграничиваем ДПС и дативно-номинативные структуры (ДНС). Частотность неадъективных предикативов ДПС типа не к лицу подсчитывается далее только для контекстов $X$-y не клицу делать $Z$, но не для контекстов $X$-y не клицу $Z{ }^{2}$

Позиция актанта в дат. п., за вычетом случаев персонификации, замещается одушевленным существительным/местоимением, о примерах типа пирогу надо остыль см. [Zimmerling $2020 \mathrm{a}$ ].

\footnotetext{
${ }^{1}$ В т.н. грамматике конструкций [Goldberg 2006] принимаются постулаты о том, что конструкцией является сложное выражение с идиоматичным значением, и о том, что выделение конструкций связано с парсингом «сверху вниз» (top down).

${ }^{2}$ Теоретические проблемы, связанные с гипотезой Поспелова, обсуждаются в [Zimmerling 2018ab], где обосновывается ее непротиворечивость.
} 
В позиции связки, помимо нулевых и ненулевых форм быть, возможны связки стать и делаться, в некоторых случаях в архаических текстах используются также глаголы приходиться и приходить. Структуры с полузнаменательными связками могут анализироваться как биклаузальные, но при обработке примеров предложения типа Мне стало холодно допустимо считать вариантами предложений типа Мне было холодно. Меньшая часть говорящих, по данным корпусного исследования [Zimmerling 2018c], допускает предложения ДПС со связкой казаться и несогласуемым предикативом, ср. 'Мне казалось холодно, 'Мне показалось удивительно, но они не соответствуют употреблению большинства. В целом, отделение стандартных употреблений от маргинальных для первых двух позиций ДПС является технической проблемой.

Иначе обстоит дело с заполнением третьей позиции. Класс предикативов ДПС пополняем, и установить, есть ли у русского предикатива валентность на дат. п., без анализа варьирования нельзя. Авторы текстов порождают примеры *мне солнечно, пыльно, но частотных употреблений с дат. п. лица у слов солнечно и пыльно нет, что подтверждается негативной реакцией большинства информантов на соответствующие примеры [Zimmerling 2017]. В то же время, у глупо есть регулярная валентность на дат. п. лица, но неясно, соответствуют ли предложения типа Мне глупо отказываться от этого значению «состояния», постулированному для конструкции ДПС. В таких предложениях дат. п. мне, на первый взгляд, указывает не на переживаемое X-м состояние, а на оценку, ср. парафразу Со стороны $X$-а глупо отказываться. Чтобы проверить гипотезу о том, что валентность на дат. п. лица диагностирует класс русских предикативов, нужно указать критерии их отбора.

\section{2 Критерии отбора предикативов}

В русском языке нет предикативов, которые реализуются исключительно в схеме $X$-y Z-во и не допускают реализаций типа Было очень $Z$-во, $Z$-во, что $P$, делать $P-Z$-во и т. п. Импликация «если русский предикатив имеет реализацию с дат. п. лица, он также имеет реализацию без дат. п.», верна.

$$
X-y Z-в о \rightarrow Z-в о .
$$

Действует ли в русском языке обратная импликация (ii), утверждающая, что для любого если предикатива может быть построен контекст с дат. п. лица, неясно.

$$
Z-в о \rightarrow X-y Z-в о .
$$

Проверка (ii) зависит от избранной модели. Базовых моделей две. Согласно первой, валентность на дат. п. задана на уровне словаря. Согласно второй, валентность на дат. п. не специфична для какого-либо класса слов и задается правилами грамматики. В [Švedova 1982: 151] ИГ в дат. п. лица трактуется как субъектный детерминант, т.е. универсальный расширитель разных схем предложения, не зависящий от конкретной лексической вершины. Другими примерами субъектных детерминантов признаются предложные группы типа для $X$ - $a$, $y X$ - $a$, и обороты типа на душе $(y X-a)$. Субъектные детерминанты можно отождествить с семантической валентностью на одушевленного субъекта, которая необязательно соответствует стандартной синтаксической валентности.

Объем активного словаря конструкции ДПС у большинства информантов, по данным социолингвистического эксперимента [Zimmerling 2017], не превышает 245 единиц, при том, что тестовый словник включал 422 стимула. Это означает, что носители языка, каждый — в своем идиолекте, отбирают предикативы ДПС на основе их семантики. Если описание грамматики ориентировано на употребление большинства, гипотеза о том, что импликация (ii) ложна, и существуют предикативы, которые не допускают сочетаний с дат. п. лица, сохраняет силу. Остается задать порог, при котором число корпусных употреблений с дат. п. лица признается незначимым. 


\section{3 Ранжирование предикативов}

Корпус, где проверяется конструкция ДПС, должен быть достаточно велик для ранжирования 300-500 единиц. Диагностика ДПС связана с отсевом омонимичных структур в контексте шире элементарного предложения. В [Zimmerling 2017] была предложена аппроксимативная мера. Число употреблений предикатива с дат. п. лица оценивалось для контекста предикатив + субъектное местоимение 1 л. ед. ч. (мне) в окне $<-1 ; 1>$. Коэффициент т указывает число диагностированных клауз ДПС в этом контексте. Для ранжирования словника по $\mathcal{M}$-мере основного корпуса НКРЯ ${ }^{3}$ достаточно. При обращении к основному корпусу НКРЯ $м$-мера дает положительные значения для 275 единиц из 422, высокочастотными можно считать 145 предикативов ДПС c $\mathrm{m} \geq 10$, все предикативы $\mathrm{c} m \geq 10$ имеют высокий рейтинг одобрения. Емкость словаря конструкции ДПС в среднестатистическом идиолекте русского языка по данным эксперимента составила 245 единиц. Этой цифре соответствуют предикативы с $\mathrm{m} \geq 2$, но надежнее положить в виде нижней гра-

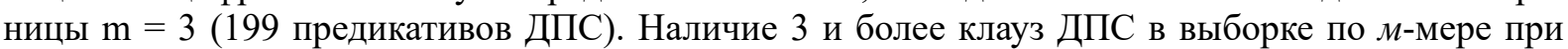
данных размерах корпуса подтверждает, что предикатив имеет регулярную валентность на дат. п. Обратное неверно: некоторые предикативы с $\mathrm{m} \leq 2$ имеют высокий рейтинг, что объясняется спецификой социолингвистических и корпусных методов. Информантам не составляет труда построить контекст, где уместны предикативы ДПС типа $X-y$ в ручье по шею, по щиколотку и т. п., но такие денотативные ситуации, особенно в режиме актуального настоящего в 1л., встречаются в корпусе редко.

\section{$2.4 \quad$ M-мера и автореферентность}

Большинство русских предикативов ДПС автореферентны, т.е. ориентированы на употребление в 1 л. в режиме актуального настоящего времени: состояние X-a фиксируется самим X-м. В русском языке свойство автореферентности связано с падежом субъекта [Zimmerling 2020b]. Предикативы ДПС, требующие дат. п., как правило, автореферентны, отражением чего является статистическое преобладание предложений в 1 л. ед. ч. с субъектным местоимением мне. Таких предложений в корпусной выгрузке обычно больше, чем предложений, где субъект выражен личным местоимением дат. п. в 2-3 л. Напротив, предикативы, требующие подлежащего в имен. п., ср. $X$ навеселе, $X$ без чувств, $X$ не в духе ориентированы на описание чужих состояний, отражением чего является обратная пропорция 1 и 3 л. в выгрузке.

Так как для большинства предикативов ДПС употребление в 1 л. является приоритетным, выборка по $\mathcal{M}$-мере дает репрезентативную картину частоты предикативов ДПС. Не все примеры контактной позиции предикатива и его субъекта (мне Z-во Z-во мне) связаны со значением актуального настоящего ${ }^{4}$, но значительная часть выгрузки относится именно к этому случаю. Синтаксическое ожидание состоит в том, что при таком линейном порядке связка будет нулевой, и, соответственно, в предложении будет выражаться настоящее время. Так, у предикатива ДПС безразлично $(\mathrm{m}=101)$ только 2 предложения $(1,98 \%)$ в выгрузке по $м$-мере имеют ненулевую связку. У предикатива ДПС холодно $(\mathrm{m}=211)$ в выгрузке по $\mathcal{M}$-мере ненулевая связка обнаруживается в 23 предложениях $(1,09 \%)$.

Предикативов ДПС, ориентированных на 3 л. или 2 л., немного, ср., жирно, слабо́, неладно, пусто, так и надо, свойственно, присуще. Если выгрузка по 2 л. и 3 л. дает большой прирост по сравнению с выгрузкой по $м$-мере, частотность предикатива ДПС в НКРЯ можно измерять, заменив мне на субъектное местоимение другого лица: так, у <Чтоб $X-y$ было $>$ nусто $2(\mathrm{~m}=1)$ замена субъектной формы мне на форму 3 л. ед. ч. ему увеличивает выгрузку в 46 раз $(\mathrm{m}=46)$. Для подавляющего большинства предикативов коррекция выгрузки по $\mathcal{M}$-мере не требуется.

\footnotetext{
${ }^{3} 23803881$ предложение на время проведения подсчетов, дата обращения 05.03.2017. В марте 2021 г. список предикативов ДПС был сверен.

${ }^{4}$ Контактный порядок ...мне $+Z$-во... допускает наличие ненулевой связки прошедшего или будущего времени или показателя сослагательного наклонения в левом или правом контексте.
} 


\section{3 Онтология конструкции ДПС и значение внутреннего состояния}

\section{1 Словник ДПС по данным эксперимента}

В [Zimmerling 2017] словарь конструкции ДПС был разбит на 15 тематических классов, в совокупности образующих онтологию конструкцию ДПС: 1) физические состояния (27 стимулов основного списка/10 стимулов дополнительного списка); 2) модальности (44/5); 3) эмоциональные состояния $(57 / 24) ; 4)$ моральные оценки $(16 / 0) ; 5)$ удобство исполнения $(8 / 0) ; 6)$ уместность/неуместность $(13 / 2), 7)$ внутренняя потребность $(7 / 2) ; 8)$ (не) соответствие задаче (11/0); 9) трудность выполнения $(10 / 4) ; 10)$ (не) желание выполнять $(9 / 1) ; 11)$ общая оценка $(41 / 7) ; 12)$ (не) релевантность $(16 / 4) ; 13)$ (не) эффективность $(6 / 1) ; 14)$ сенсорные и интеллектуальные реакции $(25 / 12) ; 15)$ параметрический признак $(52 / 8)$. Тематические группы предикатной лексики соответствуют типам денотативной ситуации. Большинство классов пополняемо, в каждом классе есть как высокочастотные и высокорейтинговые, т.е. одобренные значительным большинством информантов, предикативы, так и единицы, употребляемые лишь частью опрошенных. Классы включают не леммы, а предикатные элементы в связи с выражаемым ими значением. Так единицы $<X-y>$ плохо $_{1}$ «Х испытывает ощущение дурноты» (физическое состояние, класс 1$)$ и $<X-y>$ плохо 2 «X считает свое положение плохим» (общая оценка, класс 11) трактовались как омонимы и проверялись отдельно. Точно так же, омографы чу́дно «Х-у очень хорошо» (класс 11), и чудно́ «X-у странно» (класс 3) трактуются как разные элементы. Омонимия в пределах тематического класса не признается: если значения неудобно «Х испытывает физические неудобства при выполнении действия» (класс 5) и неудобно 2 «Х испытывает моральные затруднения» (класс 4) разводятся, они должны быть отнесены к разным классам. При корпусном анализе учитывались только ДПС типа $X$-y было не по душе, что $Y$ купил книги, а предложения типа Книги были $X-y$ не по душе игнорировались.

Для 442 стимулов получено два показателя: коэффициент $\mathrm{m}$ и рейтинг одобрения информантами. Около 145 единиц, с $\mathrm{m} \geq 10$ по НКРЯ, можно считать словарным ядром конструкции ДПС. Так как средняя емкость словаря ДПС в идиолектах опрошенных составляет 245 единиц, очевидно, что носители языка достраивают словарь ДПС самостоятельно, выбирая разные единицы, имеющие среднюю и низкую частотность в НКРЯ. В [Ivanova, Zimmerling 2019] эта онтология проверялась на материале двух языков - русского и болгарского. Болгарская конструкция ДПС, словарь которой меньше, покрывает больше денотативных ситуаций, в силу чего для нее нужны дополнительные классы онтологии. В то же время, нет никаких данных, указывающих на то, что для описания русской конструкции ДПС, нужны иные типы ситуаций: если бы это было так, им соответствовали бы тематические классы, в состав которых входили бы частотные предикативы ДПС.

\section{2 Внутренние и внешние состояния}

Состояния принято определять как разновидность локализованных во времени и пространстве событий (spatiotemporal events), занимающих отрезок на временной оси и не связанных с изменением мира от начальной до конечной точки отрезка [Davidson 1980; Bulygina 1982; Seliverstova 1982]. Л. В. Щерба и его последователи трактуют несогласуемые предикативы $(X-y)$ весело, $X$ навеселе, $X$ не в духе, и даже $X$ в сюртуке как слова <категории> состояния [Ščerba 1928; Vinogradov 1947; Lekant 2015]. Проведенное Л. В. Щербой на материале первичных предикатов различение «состояний», рус. мне весело, и «качеств» (свойств), рус. я весельй, эквивалентно выявленному Г. Карлсоном контрасту между предикатами актуализованного признака (stage-level predicates, SLP), которые обозначают временные характеристики референтных ситуаций, cp. англ. There are firemen available «пожарные (в данный момент) доступны» и предикатами индивидного признака (individual-level predicates, ILP), которые обозначают свойства, отвлеченные от конкретных ситуаций, ср. невозможность англ. *There are firemen altruistic, подр. зн. «В данный момент пожарные альтруистичны» [Carlson 1977]. Контраст между SLP и ILP преимущественно иллюстрируется на материале вторичных предикатов [Kratzer 1995; Kosta 2014; 2020], что мешает осознанию эквивалентности дэвидсоновских/щербовских состояний и SLP-предикатов в традиции Г. Карлсона. 
Для описания специфики предикативов ДПС требуется дополнительное различение внешних и внутренних состояний. Термин «внутренние состояния» был введен в [Zaliznjak 1995] для группы глагольных значений и использован для классификации именных предикатов в [Zimmerling 2018a]. Внутренние состояния обозначают ситуации с приоритетным одушевленным аргументом, в то время как у внешних состояний нет приоритетного аргумента, независимо от одушевленности и местности предиката (ср. Здесь пыльно, Х дружит с Y-м). Релевантное отличие состоит в том, что внутренние состояния нельзя квантифицировать экстенсионально: в одном и том же локусе в одно и то же время X-у может быть холодно и скучно, а Y-y — нет. Кроме того, внутренние состояния, в отличие от внешних, не характеризуют визуально и аудиально воспринимаемые ситуации. Напротив, предикаты внешнего состояния типа $<3$ десь $>$ nыльно; $<c e z o-$ дня $>$ пасмурно обозначают ситуации, где любой наблюдатель подтвердит, что высказывание истинно.

\section{3 Смена семантического типа}

\subsection{1. От внешнего состояния к внутреннему}

Переход $\mathrm{S}_{\mathrm{ExT}} \rightarrow \mathrm{S}_{\mathrm{INT}}$ в истории русского языка подтверждается тем, что число основ, от которых могут быть образованы предикативы ДПС, за последние 500 лет увеличилось в несколько раз [Zimmerling 2018b]. Вместе с тем, в каждый момент времени в большинстве идиолектов сохраняются основы типа пыльн-, пасмурн-, от которых предикативы ДПС не образуются.

\subsection{2. От внутреннего состояния к внешнему}

Переход $\mathrm{S}_{\mathrm{INT}} \rightarrow \mathrm{S}_{\mathrm{EXT}}$ может реализоваться за счет устранения внешне выраженного субъекта. В русском языке нет конструкций с обязательным местоименным экспериенцером, cp. [Ivanova 2016]. Один и тот же предикатив может реализоваться и в ДПС в значении $\mathrm{S}_{\mathrm{INT}}$, и в схеме без семантического субъекта в значении $\mathrm{S}_{\mathrm{EXT}}$. Сдвиг $\mathrm{S}_{\mathrm{INT}} \rightarrow \mathrm{S}_{\mathrm{EXT}}$ при опущении внешне выраженного субъекта автоматически, но контексты, где значения « $X-y Z$-во» vs «Z-во» разделены, существуют. В примере (1) говорящий противопоставляет значения «смешно с точки зрения любого человека» $(\varnothing$ смешно) и «смешно конкретному человеку» (смешно мне):

(1) И какая все это беспорядица, неурядица, глупость и пошлость, и я всему причиною. А впрочем, иногда бывает $\varnothing$ смешно $\left(\mathrm{S}_{\mathrm{EXT}}\right)$ - мне $\left(\mathrm{S}_{\mathrm{INT}}\right)$ по крайней мере.

[Ф. М. Достоевский. Игрок (1866)].

\section{4 Предикаты состояния в НКРЯ}

Возможность образования вторичных внутренних состояний от внешних ( $\mathrm{S}_{\mathrm{EXT}} \rightarrow \mathrm{S}_{\mathrm{INT}}$ ) проверяется путем выявления порога регулярности такого перехода в НКРЯ. В разделе 4.1. приводятся данные для 50 предикатов внешних состояний. Проверка обратного перехода $\mathrm{S}_{\mathrm{INT}} \rightarrow \mathrm{S}_{\mathrm{EXT}}$ требует семантической аннотации. В п. 4.2.-4.4. доказывается, что предикатив тоскливо и коррелятивное ему наречие могут передавать значение $\mathrm{S}_{\mathrm{EXT}}$ при устранении субъекта из схемы предложения.

\section{1 Пополнение словаря ДПС}

На материале НКРЯ в 2021 г. проверялись ограничения на употребление 50 предикативов внешнего состояния. 5 единиц входило в дополнительный список стимулов, для которых в [Zimmerling 2017] получены низкие оценки приемлемости употреблений с дат. п. лица: Гипотеза состояла в том, что если переход $\mathrm{S}_{\mathrm{EXT}} \rightarrow \mathrm{S}_{\mathrm{INT}}$ для предикатива затруднен, число клауз ДПС в выборке по $\mathcal{M}$-мере должно быть $0<\mathrm{m}<3$, т.е. ниже порога, подтверждающего включение элемента в словарь ДПС. Прогноз оправдался для 49 предикативов из 50. Для сухо $\mathrm{m}=3$, при этом в контекстах Здесь сухо ( $\left.\mathrm{S}_{\mathrm{EXT}}\right)$ и Мне сухо ( $\left.\mathrm{S}_{\mathrm{INT}}\right)$ реализуются разные лексические значения: в двух примерах из трех предложение ДПС значит 'мне нужно выпить', ср. (2):

(2) И не крикнет покойник, встав со смертного ложа: други, сухо мне! [М. Шагинян. Перемена (1959)]. 
Контексты типа (2) были незнакомы части опрошенных, чем объясняется низкий рейтинг одобрения. Для сравнения, у предикатива $X-y$ мокро, включенного в основной список эксперимента 2017 г. и одобренного 12 информантами из 18, $\mathrm{m}=1$, при 21 предложениях ДПС в НКРЯ. Тем самым, ни $X-y$ cyxo, ни $X-y$ мокро не относятся к словарному ядру конструкции. Чтобы оценить употребления ДПС для 50 проверявшихся предикативов, нужно сопоставить три показателя общее число вхождений в корпус, число клауз ДПС и коэффициент $\mathrm{m}$.

\begin{tabular}{|c|c|c|c|c|}
\hline & Предикативы & $\begin{array}{l}\text { Число } \\
\text { вхождений } \\
\text { в НКРЯ }\end{array}$ & $\begin{array}{l}\text { Число } \\
\text { клауз } \\
\text { ДПС }\end{array}$ & $\mathrm{m}$ \\
\hline$m>1$ & cyxo & 235 & $\begin{array}{l}6 \\
(2,55 \%)\end{array}$ & 3 \\
\hline $\mathrm{m}=1$ & $\begin{array}{l}\text { пыльно, свежсо, скользко, пустынно, морозно, } \\
\text { тряско, бездомно }\end{array}$ & 1900 & $\begin{array}{l}34 \\
(1,79 \%)\end{array}$ & 1 \\
\hline $\mathrm{m}=0$ & $\begin{array}{l}\text { солнечно, знойно, облачно, пасмурно, дождливо, } \\
\text { болотисто, туманно, мәлисто, ветрено, про- } \\
\text { мозгло, влажно, сыро, хмуро, склизко, липко, без- } \\
\text { людно, снежно, бесснежно, безветрено, людно, } \\
\text { лунно, звездно, беззвездно, сумрачно, грязно, } \\
\text { росно, росисто, топко, рыхло, вязко, гористо, } \\
\text { лесисто, каменисто, терпко, вонько, вонюче, } \\
\text { зловонно, парко, тинисто, дымно, смрадно, } \\
\text { чадно, вьюжно, тенисто, слякотно, угарно }\end{array}$ & 4572 & $\begin{array}{l}35 \\
(0,76 \%)\end{array}$ & 0 \\
\hline
\end{tabular}

Таблица 1. Предикаты внешнего состояния в контексте $\mathrm{S}_{\mathrm{INT}}$

Анализ подтвердил, что переход $\mathrm{S}_{\mathrm{EXT}} \rightarrow \mathrm{S}_{\mathrm{INT}}$ в большинстве идиолектов русского языка затруднен. Построение вторичного предикатива ДПС типа ?? $X$-у пыльно не запрещено, но эксперименты носителей языка с помещением предикатов внешнего состояния в контекст, характерный для $\mathrm{S}_{\mathrm{INT}}$, обычно не востребованы другими носителями и относятся к зоне индивидуального варьирования.

\section{$4.2 \quad$ Переход $\mathrm{S}_{\mathrm{INT}} \rightarrow \mathrm{S}_{\mathrm{EXT}}$}

Переход $\mathrm{S}_{\mathrm{INT}} \rightarrow \mathrm{S}_{\mathrm{EXT}}$ демонстрируется на примере предикатива тоскливо. Концепт тоски описан в [Wierzbicka 1992: 169-174; Šmelev 2002: 90-92; Zaliznjak 2006: 207; Zaliznjak, Levontina, Šmelev 2012: 41; Zaliznjak 2013: 41, 376].

\subsection{1. Тоскливо 2 как предикат внутреннего состояния}

НКРЯ, на март 2021 г., указывает 3133 вхождений тоскливо в качестве предикатива, согласуемого прилагательного ср. р. и наречия: их следует вводить как разные леммы. Для обработки была доступна выборка из 1632 клауз, самые ранние примеры относятся к 1909 г. В этой выборке $\mathrm{m}=23$, что позволяет отнести тоскливо 2 к ядру ДПС. По [Zimmerling 2017], 83,3\% информантов (15 из 18) активно используют тоскливо 2 как $\mathrm{S}_{\mathrm{NT}}$. Распределение синтаксических структур указано в таб. 2. Обращает на себя внимание ничтожное $(0,06 \%)$ число примеров с прилагательным тоскливо 1 и нетривиальное соответствие между дат.п. лица и наличием оборота на сердие/на душе $(y X-a)$, указывающим на субъект состояния. В 307 клаузах ДПС такой оборот встретился 1 раз $(0,32 \%)$, в то время как в клаузах без дат. п., доля примеров с ним составила $14,47 \%$. Выгрузка наречия тоскливо фикатора прилагательного или другого наречия, ср. тоскливо-щемящий; б) тоскливо з в позиции элемента глагольной группы (vP, VP) или включающей ее группы функциональной категории предложения. 


\begin{tabular}{|c|c|c|c|c|c|c|}
\hline \multirow{3}{*}{$\begin{array}{l}\text { І.Краткое } \\
\text { прил. ср.p. } \\
\text { тоскливо }\end{array}$} & \multicolumn{4}{|c|}{ II. Предикатив тоскливо } & \multirow{2}{*}{\multicolumn{2}{|c|}{$\begin{array}{c}\text { III. } \\
\text { Носкливечие } \\
\text { ооскив }_{3}\end{array}$}} \\
\hline & \multicolumn{2}{|c|}{ ДПС } & \multicolumn{2}{|c|}{ без дат. п. } & & \\
\hline & $\begin{array}{l}+ \text { на } \\
\text { душе }\end{array}$ & $\begin{array}{c}\text { без расши- } \\
\text { рителя }\end{array}$ & $\begin{array}{c}+ \text { на } \\
\text { душе/на } \\
\text { сердие }\end{array}$ & $\begin{array}{c}\text { без расшири- } \\
\text { теля }\end{array}$ & $\begin{array}{c}\mathrm{ADV} 1 \\
\left(\mathrm{ADJ} / \mathrm{ADV}_{2}\right)\end{array}$ & $\mathrm{vP}, \mathrm{VP}$ \\
\hline \multirow[t]{2}{*}{1} & $\begin{array}{c}1 \\
(0,32 \%)\end{array}$ & 306 & $\begin{array}{c}59 \\
(14,47 \%)\end{array}$ & 343 & 38 & 885 \\
\hline & \multicolumn{2}{|c|}{307} & \multicolumn{2}{|c|}{402} & \multicolumn{2}{|c|}{923} \\
\hline
\end{tabular}

Таблица 2. Прилагательное, предикатив и наречие тоскливо в НКРЯ

Предложения с тоскливо 2 , где есть один из маркеров субъекта состояния - группа со значением дат.п. лица или оборот на душе/на сердие - либо оба, можно отождествить с $\mathrm{S}_{\mathrm{INT}}$, их доля составляет $50,63 \%$ от выгрузки тоскливо 2 . Вместе с тем, отсутствие данных маркеров еще не свидетельствует, что тоскливо 2 передает значение $\mathrm{S}_{\mathrm{EXT}}$.

\subsection{2. Семантические и синтаксические актанты}

Оборот на душе/на сердие при тоскливо 2 указывает на одушевленного участника, но в отличие от беспредложного дат. п. лица, не выступает в роли приоритетного синтаксического актанта. Оборот на душе/на сердие находится в дополнительной дистрибуции с сентенциальной валентностью. Допускаются структуры типа (Мне) было тоскливог (на дуще) и типа (мне) было тоскливо выходить из дому, но не структуры типа *было тоскливо на душе выходить из дому.

\begin{tabular}{|c|c|c|c|c|c|}
\hline \multicolumn{3}{|c|}{ Предикативы ДПС (307) } & \multicolumn{3}{|c|}{ Предикативы без дат.п. лица (402) } \\
\hline \multirow{2}{*}{+ на душе (1) } & без расширителя (306) & \multirow{2}{*}{ на душе/на } & без расширителя (343) \\
\cline { 2 - 3 } cердие (59) & что $P$ & инфинитив & & инфинитив \\
\hline 0 & $1(0,32 \%)$ & $13(4,24 \%)$ & 0 & $2(0,49 \%)$ & $57(16,61 \%)$ \\
\hline
\end{tabular}

Таблица 3. Сентенциальные валентности предикатива тоскливо , по НКРЯ

\section{3. Ориентащия на 1-е лищуо}

В 78,5\% случаев позиция дат.п. лица при тоскливо з замещается личным местоимением (245 примеров из 307). При контактной позиции местоимения доля высказываний в 1 л. составляет 48\% (24 из 50), при дистантной - 61,78\% (118 из 191). Эти данные согласуются с гипотезой о том, что тоскливо 2, как и большинство русских предикативов ДПС - автореферентное слово, ориентированное на описание состояния говорящего.

\section{3 Тоскливо 2 как внешнее состояние}

Не менее 52 примеров выборки строится по схеме Z-е тоскливо и и выражает значение $\mathrm{S}_{\mathrm{EXT}}$. Некоторые примеры можно рассматривать как рефлексию над тем фактом, что тоскливо 2 параллельно употребляется как в значении $\mathrm{S}_{\mathrm{INT}}$, так и в значении $\mathrm{S}_{\mathrm{EXT}}$.

(3) Тоскливо все и внутри Феликса, и вокруг него. [А. Ростовский. По законам волчьей стаи (2000)].

(4) Выло в трубе, и становилось тоскливо на душе. [К. С. Станиславский. Работа актера над собой (1938)].

В (3)-(4) неясно, оценивается ли референтная ситуация с точки зрения конкретного вовлеченного в нее человека - Феликса в (3), рассказчика в (4), или же любого наблюдателя. Если одушевленного участника нет, вторая интерпретация является единственной. 


\section{4 Наречие тоскливо 3 и структура события}

Употребление тоскливо 2 служит базовым контекстом для толкования наречия тоскливоз. Ситуации, описываемые тоскливоз и тоскливо 2, подразумевают два типа одушевленных участников. Одним из них является субъект состояния $(\mathrm{X})$, который может быть не выражен синтаксически, но реконструироваться однозначно, например, при имени аффекта воспоминание в (5):

(5) Яркое воспоминание $(\rightarrow \mathrm{X})$ тоскливо стеснило грудь $(\rightarrow \mathrm{X})$, но Гирин $(\mathrm{X})$ отбросил его. [И. А. Ефремов. Лезвие бритвы (1959-1963)].

Вторым типом одушевленного участника, обычно остающимся имплицитным, является наблюдатель, он же субъект оценки (Y). Пример (6) допускает только одну интерпретацию, когда оценка присваивается наблюдателем, в роли которого может выступить любой человек:

(6) Негромкий звук выстрела $(\rightarrow Y)$ одиноко и тоскливо прокатился эхом по лесу и иссяк где-то вдали. [В. Кондратьев. Сашка (1979)].

При наличии одушевленного участника предложение становится амбивалентным. Так, пример (7) описывает ситуацию, где на улице мерзнут некие милиционеры (X). Эта ситуация доступна внешнему наблюдению и может отражать точку зрения стороннего наблюдателя, стоящего на противоположной стороне улицы $(\mathrm{Y})=$ «Было тоскливо 2 ( $\left.\mathrm{S}_{\mathrm{EXT}}\right)$ смотреть, как на улице мерзли милиционеры». Но она может также отражать перспективу самого X-a, в этом случае толкование будет содержать отсылку к внутреннему состоянию - «На улице мерзли милиционеры, и им было тоскливо 2 ( $\left.\mathrm{S}_{\mathrm{INT}}\right) »$.

(7) На противоположной стороне улищы $(\rightarrow Y)$ тоскливо мерзли три милиционера $(\rightarrow X)$. [Е. Строителева. «Иисус, как и Ленин, добра людям хотел» (2002) // «Известия», 2002.11.08].

\section{5 Заключение}

На материале НКРЯ была проверена модель варьирования грамматической конструкции, опирающуюся на онтологию данной конструкции. Ограничение поиска выделенным контекстом контактной позицией предикатива и субъектного местоимения 1 л. ед.ч. — позволяет установить порог, при котором употребления предикатива с дат.п. лица могут считаться значимыми. Регулярные семантические переходы работают только в одну сторону - от внутренних состояний к внешним, но не в обратном направлении. При устранении дат.п. лица предикатив может описывать внешне наблюдаемую ситуацию, оцениваемую одинаково любым наблюдателем. Глагольные предложения с качественным наречием, коррелятивным предикативу, проецируют структуру события, содержащую отсылку либо к внутреннему, либо к внешнему состоянию.

\section{References}

[1] Bulygina Tatiana V. (1982). Towards Predicate Typology in Russian [K Postroeniyu Tipologii Predikatov v Russkom Jazyke], O. N. Seliverstova (ed.), Semantic types of the predicates [Semanticheskie Tipy Predikatov], Moscow, Nauka, 1982, pp. 7-85.

[2] Carlson Greg. Reference to Kinds in English. PhD dissertation. — MIT, 1977.

[3] Davidson Donald. The Individuation of Events // D. Davidson (ed.) Essays on Actions and Events. Oxford, Clarendon Press, 1980. - P. 163-180.

[4] Goldberg Adele. Constructions at Work: the Nature of Generalization in Language. — Oxford, OUP, 2006.

[5] Henry Alison. Non-standard Dialects and Linguistic Data // Lingua, vol. 115, 2005. - P. 1599-1617.

[6] Ivanova Elena Yu. (2016). Impersonal Sentences with an Obligatory Pronominal Experiencer in Bulgarian [Bezlichnye Predlozheniya s Obyazatel'nym Mestoimennym Vyrazheniem Eksperiencera v Bolgarskom Jazyke], A.V.Zimmerling, E.A.Lyutikova (eds.), Clause Architecture in the Parametric Models. Syntax, Information Structure, Word Order, [Arxitektura Klauzy v Parametricheskix Model'ax: Sintaksis, Informacionnaya Struktura, Por'adok Slov], Moscow, LRC, pp. 332-68. 
[7] Ivanova Elena Yu., Zimmerling Anton V. Shared by All Speakers? Dative Predicatives in Bulgarian and Russian // Bulgarski Language and Literature, № 4, 2019. — P. 353-363.

[8] Kosta Peter. Adjectival and Adjectival and Argumental Small Clauses vs. Free Adverbial Adjuncts. A PhaseBased Approach within the Radical Minimalism with Special Criticism of the Agree, Case and Valuation Notions. - 2014. - Access mode: https://www.semanticscholar.org/paper/Adjectival-and-argumentalSmall-Clauses-vs.-free-\%E2\%80\%93-Kosta/1c5b2340f433d01c17eb689ae579cfab8313b61f

[9] Kosta Peter. The Syntax of Meaning and the Meaning of Syntax: Minimal Computations and Maximal Derivations in a Label-/Phase-Driven Generative Grammar of Radical Minimalism. Potsdam Linguistic Investigation 31. - Berlin: Peter Lang, 2020.

[10] Kratzer Angelica. Stage Level and Individual Level Predicates // Carlson G. \& Pelletier F.J. (eds.): The Generic Book. - Chicago: The University of Chicago Press, 1995. - P. 125-175.

[11] Lekant Pavel A. (2015). Analytical Forms and Analytical Constructions in Modern Russian [Analiticheskie Formy i Analiticheskie Konstrukcii v Sovremennom Russkom Jazyke], Moscow, Inform.

[12] Pospelov Nikolai S. (1955). In Defence of the State Category [V Zasch'itu kategorii Sostojaniya], Issues in Linguistics [Voprosy Jazykoznaniya], № 2, pp. 55-65.

[13] Ščerba Lev V. (1928). On Parts of Speech in Russian [O Chastyax Rechi v Russkom jazyke], Russian Speech. New Series, II [Russkaja Rech'. Novaja Seriya], — Leningrad, Academia, — pp. 5 - 27.

[14] Šmelev Alexei. D. (2002). Russian Natural Language Metaphysics. Preliminaries for a Dictionary [Russkaja Jazykovaya Model' Mira. Materialy k Slovar'yu], Moscow, LRC.

[15] Seliverstova Olga N. (2002). An Alternative Variant of the Predicate Taxonomy and Some Predicate Types in Russian [Vtoroj Variant Klassifikacionnoj Setki i Opisanie Nekotoryx Predikatnyx Tipov Russkogo Jazyka], O.N.Seliverstova (ed.), Semantic Types of the Predicates [Semanticheskie Tipy Predikatov], Moscow, Nauka, pp. 86-157.

[16] Švedova Nina Yu. (1982). Russian Grammar. In 2 vols. Vol 2 [Russkaja Grammatika, N.Yu.Shvedova (ed.)], Moscow, Nauka.

[17] Vinogradov Victor V. (1947). Russian Language. The Grammatical Theory of a Word [Russkij Jazyk. Grammaticheskoe Uchenie o Slove], Moscow- Leningrad, Vysšaya škola.

[18] Wierzbicka Anna. Semantics, Culture and Cognition: Universal Human Concepts in Culture-specific Configuration. - N.Y., 1992.

[19] Zaliznjak Anna A. (1995). Studies in the Semantics of the Predicates of the Inner States [Issledovaniya po Semantike Predikatov Vnutrennego Sostoyaniya], München, Otto Sagner.

[20]Zaliznjak Anna A. (2006). Polysemy in language and its modeling [Mnogoznachnost'v Jazyke i Sposoby Eje Predstavleniya], Moscow, LRC.

[21]Zaliznjak Anna A. (2013). Russian Semantics from a Typological Perspective [Russkaja Semantika v Tipologicheskoj Perspektive], Moscow, LRC.

[22] Zalizjak Anna A., Levontina Irina B., Šmelev Alexei D. (2012). Constants and Variables in the Russian Natural Language Metaphysics [Konstanty i Peremennye Russkoj Jazykovoj Kartiny Mira], Moscow, LRC.

[23]Zimmerling Anton V. (2017). Russian Predicatives from the Perspective of an Experiment and Corpus Grammar [Russkie Predikativy v Zerkale Eksperimenta i Korpusnoj Grammatiki], Computational Linguistics and Intellectural Technologies, Issue 16 (23) [Komp'yuternaja Lingvistika i Intellektual'nye Tekhnologii: Trudy Mezhdunarodnoy Konferentsii “Dialogue 2017”], Moscow, pp. 466 — 482.

[24]Zimmerling Anton V. (2018a), Predicatives and Predicates of State in Russian [Predikativy i Predikaty Sostojanija v Russkom Jazyke], Slavic Review [Slavistična Revija], № 1, pp. 45-64.

[25]Zimmerling Anton V. (2018b), Impersonal Constructions and Dative-predicative Structures in Russian [Impersonal'nye Konstrukcii i Dativno-predikativnye struktury v Russkom Jazyke] // Issues in Linguistics [Voprosy Jazykoznaniya], № 5, pp. 7-33.

[26] Zimmerling Anton V. (2018c). Two dialects of Russian. Corpus grammar and a formal model [Dva Dialekta Russkoy Grammatiki: Korpusnye Dannye i Model'], Computational Linguistics and Intellectural Technologies, Issue 17 (24) [Komp'yuternaja Lingvistika i Intellektual'nye Tekhnologii: Trudy Mezhdunarodnoy Konferentsii “Dialogue 2018”], Moscow, pp. 818 - 833.

[27] Zimmerling Anton V. (2020a). Animacy. Russian Language [Odushevlennost'. Russkij Jazyk], Proceedings of the Vinogradov Russian Language Institute [Trudy Instituta Russkogo Jazyka Imeni V.V.Vinogradova RAN], issue 24, pp. 43-56.

[28] Zimmerling Anton V. (2020b). Autoreferentiality and Predicate Classes [Aftoreferentnost' i Klassy Predikativnyx Slov], M.D.Voejkova, V.V.Kazakovskaya (eds.), Issues in Functional Hrammar. Reference to the Speaker in Grammatical Seemantics, [Problemy Funkcional'noy Grammatiki: Otnoshenie k Govor'jaschemu v Semantike Grammaticheskix Katerogorij, Moscow, LRC, pp. 23-58. 


\section{Литература}

[1] Carlson Greg. Reference to Kinds in English. PhD dissertation. — MIT, 1977.

[2] Davidson Donald. The individuation of events // D. Davidson (ed), Essays on Actions and Events. Oxford, Clarendon Press, 1980. - P. 163-80.

[3] Goldberg Adele. Constructions at Work: the Nature of Generalization in Language. — Oxford, OUP, 2006.

[4] Henry Alison. Non-standard Dialects and Linguistic Data // Lingua, vol. 115, 2005. — P 1599-1617.

[5] Ivanova Elena Yu., Zimmerling Anton V. Shared by All Speakers? Dative Predicatives in Bulgarian and Russian // Bulgarski Language and Literature, № 4, 2019. — P. 353-363.

[6] Kosta Peter. Adjectival and Adjectival and argumental Small Clauses vs. free adverbial Adjuncts. A phasebased approach within the Radical Minimalism with special criticism of the Agree, Case and Valuation notions. - 2014. Access mode: https://www.semanticscholar.org/paper/Adjectival-and-argumental-SmallClauses-vs.-free-\%E2\%80\%93-Kosta/1c5b2340f433d01c17eb689ae579cfab8313b61f

[7] Kosta Peter. The Syntax of Meaning and the Meaning of Syntax: Minimal Computations and Maximal Derivations in a Label-/Phase-Driven Generative Grammar of Radical Minimalism. Potsdam Linguistic Investigation 31. - Berlin: Peter Lang, 2020.

[8] Kratzer Angelica. Stage Level and Individual Level Predicates // Carlson G. \& Pelletier F.J. (eds.): The Generic Book. - Chicago: The University of Chicago Press, 1995. - P. 125-175.

[9] Wierzbicka Anna. Semantics, Culture and Cognition: Universal Human Concepts in Culture-specific Configuration. - N.Y., 1992.

[10]Булыгина Т.В. К построению типологии предикатов в русском языке // О.Н.Селиверстова (ред.). Семантические типы предикатов. - Москва: Наука, 1982. - С. 7-85.

[11] Виноградов В.В. Русский язык. Грамматическое учение о слове. - Москва - Ленинград: Высшая школа, 1947.

[12]Иванова Е.Ю. Безличные предложения с обязательным местоименным выражением экспериенцера в болгарском языке // А.В.Циммерлинг, Е.А.Лютикова (ред.), Архитектура клаузы в параметрических моделях: синтаксис, информационная структура, порядок слов. - Москва: Языки славянской культуры, 2016. - С. 332-368.

[13]Зализняк Анна А. Исследования по семантике предикатов внутреннего состояния. — München, Otto Sagner, 1995.

[14]Зализняк Анна А. Многозначность в языке и способы ее представления. Москва: Языки славянской культуры, 2006.

[15] Зализняк Анна А. Русская семантике в типологической перспектива. — Москва: Языки славянской культуры, 2013.

[16] Зализняк Анна А., Левонтина И.Б., Шмелев А.Д. Константы и переменные русской языковой картины мира. - Москва: Языки славянской культуры, 2012.

[17] Лекант П.А. Аналитические формы и конструкции в современном русском языке. -Москва: Информ, 2015.

[18] Поспелов Н.С. В защиту категории состояния // Вопросы языкознания, 1955, № 2. — С. 55-65.

[19] Селиверстова О.Н. Второй вариант классификационной сетки и описание некоторых предикатных типов русского языка // О.Н.Селиверстова (ред.), Семантические типы предикатов. - Москва: Наука, 1982. - С. 86-157.

[20] Шведова Н.Ю. (ред.). Русская грамматика. В 2 т. - Т. 1. - Москва: Наука, 1982.

[21] Шмелев А.Д. Русская языковая модель мира. Материалы к словарю. - Москва: Языки славянской культуры, 2002.

[22] Щерба Л.В. О частях речи в русском языке // Русская речь. Новая серия. - Ленинград: Асаdemia, 1928. - C. 5-27.

[23] Циммерлинг А.В. Русские предикативы в зеркале эксперимента и корпусной грамматике // Компьютерная лингвистика и интеллектуальные технологии. - Вып. 16 (23). Труды международной конференции «Диалог 2017». - Москва, 2017. - С. 466-482.

[24] Циммерлинг А.В. (2018a). Предикативы и предикаты состояния в русском языке // Slavistična Revija, № 1, 2018. - P. $45-64$.

[25] Циммерлинг А.В. (2018b), Имперсонвальные конструкции и дативно-предикативные структуры в русском языке // Вопросы языкознания, № 5, 2018. - С. 7-33.

[26] Циммерлинг А.В. (2018c). Два диалекта русской грамматики: корпусные данные и модель // Компьютерная лингвистика и интеллектуальные технологии. - Вып. 17 (24). Труды международной конференции «Диалог 2018». - Москва, 2018. - С. 818-833.

[27] Циммерлинг А.В. (2020а). Одушевленность. Русский язык // Труды Института русского языка имени В.В.Виноградова РАН. - Вып. 24, 2020. - С. 43-56.

[28] Циммерлинг А.В. (2020b). Автореферентность и классы предикативных слов // М.Д.Воейкова, В.В.Казаковская (ред.). Проблемы функциональной грамматики. Отношение к говорящему в семантике грамматических категорий. - Москва: Языки славянской культуры, 2020b. - Москва: Языки славянской культуры, 2020. - С. 23-58. 